\title{
Integrated task on students' writing quality: Is it more effective?
}

\author{
Hieronimus Canggung Darong \\ Universitas Katolik Indonesia Santu Paulus, Jalan Ahmad Yani 10 Manggarai NTT Tenda, Watu, Ruteng, Kabupaten Manggarai, \\ Nusa Tenggara Tim. 86511, Indonesia \\ hieronimusdarong@gmail.com
}

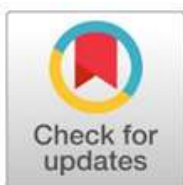

\section{ARTICLE INFO}

Article history

Received 04 January 2021

Revised 29 March 2021

Accepted 20 April 2021

Keywords

independent task

integrated task

quality of writing

\section{ABSTRACT}

Integrated tasks are popularly known and accepted as an effective way of improving students' writing quality. However, it is still not clear to what really accounts for its effectiveness. This study examined whether the students who were facilitated by integrated task achieved higher writing quality than those who were not. Twenty - two students participated within the group experiment utilizing a counterbalance technique in controlling the order effect. In the first session, twelve students were asked to write an essay based on an integrated (INT) task while the other 12 wrote based on an independent (IND) task. Then, the task division was switched in the second writing session. Students' writing quality were scored by three raters and were analyzed descriptively and inferentially using Wilcoxon signed rank test (WSRT). The results confirmed that the quality of students' writing using both integrated and independent tasks was not significantly different. There are still other aspects contributing to writing quality. Thus, task types do not guarantee the students' writing quality.

This is an open access article under the CC-BY-SA license.

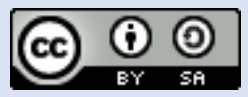

How to Cite: Darong, H.C. (2021). Integrated task on students' writing quality: Is it more effective? English Language Teaching Educational Journal, 4(1), 25-33. doi.org/10.12928/eltej.v4i1.3336

\section{Introduction}

A great number of research studies have been focusing on the role of task design in foreign or second language learning, (In'nami \& YoKoizumi, 2016; Leaper, 2014; Nitta \& Nakatsuhara, 2014). The interest is mainly inspired by the learners' experiences as well as teachers' expectation regarding the quality of the spoken performance. Yet, many studies on writing are becoming increasingly familiar and have already widely seen as a great source of writing inquiry. Writing, as the field of the second language, considers the authenticity and meaningfulness of connecting writing with other skills (Plakans, 2010).

Traditionally, writing assesses other skills independently and examines global construct and individual experiences in response to a given exposure. This old-fashioned type of measurement was changed into the integrated one. Writing, then, was not seen as an isolated, solitude construct, and independent assessment task. The skill of writing is not concerned with autonomous but, rather allied with reading, listening and speaking (Plakans, 2010).

Integrated writing tasks that include distinctive language skills such as both reading and listening skills are mostly considered as tools to determine the writing quality academically. They are predominantly investigated by many researchers in relation to language writer's strategy use and performance (GhaVamnia, Tavakoli, \& Esteki, 2013; Gu, 2014; Yang \& Plakans, 2012)(Grace \& Malang, 2018), task representation, (Pertiwii, Dian, Ngadiso, \& Drajat, 2018; Plakans, 2010; Shi \& 
Ma, 2016) and scoring system in conjunction with writing performances of different context, (Gebril \& Plakans, 2013; Knoch \& Sitajalabhorn, 2013; Sawaki, Quinlan, \& Lee, 2013; Wolfersberger, 2013).

However, the investigation on the quality of writing was, in fact, carried out and was considerably influenced by various factors such as the strategy of giving task to the students, (Abrams \& Byrd, 2017; Rassaei, 2014; Thi, Nguyen, Pham, \& Pham, 2015; Wette, 2014) and accounts for task scores and rater skills effect, (Barkaoui, 2014; In'nami \& YoKoizumi, 2016; Ling, Mollaun, \& Xi, 2014; Plakans, Gebril, \& Bilki, 2016; Shin \& Ewert, 2015; Yan, 2014). The test takers' proficiency level and comprehensive corrective feedback, (Cho, Rijmen, \& Novak, 2013; Kuiken \& Vedder, 2014; Zhang, 2017) were also the main concern of the previous research studies.

Even though there have been many research findings showing attention toward writing, most of them are focusing on the way of teaching writing which is considered as partial study due to their target at linguistic features. As such, there is a tendency to regard it as explicit knowledge through an explicit instruction. This present study, on the other hand, concerned the integrated task of writing in which explicit knowledge carried out in a focused task of implicit instruction. Besides, the findings on the effectiveness of integrated task might not be definitely generalized to the participants' education level. Most of the previous findings found that it is more effective than independent task as it was applied on the secondary level and the students who took the admission test to the university. However, this result is still questionable for its consistency if it is applied to a different level of students, for example, college students who have learned English for a long period of time.

Based on the aforementioned gap, this study aims to know whether the college students who are facilitated by integrated task achieve higher writing quality than those who are facilitated by independent task. Then, the study might contribute to teacher viewpoints in employing a particular task type for teaching writing. In this respect, the task type should be constructed in such a way that it might be of benefit for improving students' writing quality.

\section{Integrated Task}

In practice, integrated task cannot be separated from independent task. To measure students writing quality, the task type in question has been broadly utilized to see the students writing quality. Students are required to make an essay independently and examine global construct and individual experiences without having any exposures. Even though it is a challenging work, learning to write through such a task type is widely practiced for teachers to gain students' writing quality. Yet, as time went by, this old-fashioned type of measurement was changed into the integrated one. Writing, then, was not seen as an isolated, solitude construct, and independent assessment task. The skill of writing is not concerned with being autonomous but, rather allied with reading, listening and speaking or being integrated, (Plakans, 2010).

With respect to the remodeling highlighted above, there have been many definitions of integrated task proposed by scholars. For example, integrated task is a sort of task in which test takers are asked to compose a certain text that display appropriate and meaningful uses of and orientations to source evidence, both conceptually such as apprehending, synthesizing, and presenting source ideas from the text and textually involving stylistic conventions for presenting, citing, and acknowledging, (Cumming et al.2005). Meanwhile, highlighting the construct of reading-to-write tasks, it is regarded as an instructional task combining reading and writing for various educational purposes (Delaney, 2008). Meanwhile, Plakans (2009) has provided the conception by involving other skills. Integrated writing task is the task type which elicits writing performance that includes other aspects such as reading or listening abilities. Furthermore, in her other work, a very broad definition is proposed that is a task requiring more than one skill for completion (Yang \& Plakans, 2012). In the most detailed definition, Integrated writing task is a task type in which test-takers are provided with one or more language- rich source texts and are asked to compose an essay requiring extraction of the source texts for opinions, choosing and constructing ideas, synthesizing ideas from one or more source texts, transfiguring the language used in the input, managing opinions and utilizing stylistic conventions such as linking ideas and recognizing sources. The rating scale employed to grade such an essay needs to consider these features specific to integrated writing tasks (Knoch \& Sitajalabhorn, 2013). In short, the definitions provided above have confirmed that integrated task particularly in writing task has been well- defined in the issue of skill combination and source use. 
With such conceptions mentioned above, integrated writing tasks have been assumed widely as an effective task to measure student writing quality. Then, it is not surprising this type of task has been largely used by the teachers to examine students' writing quality. They are provided with reading material and require students to construct a text based on the information given in the text. Subsequently, the questions are given to the students for the sake of their text. (Knoch \& Sitajalabhorn, 2013). In other words, the students are required to summarize the text given by the guidance of predetermined questions. A modification of the task in question is a reading stimulus with two or more texts. In this regard, learners might compose to synthesize several source texts or confront ideas on the similar issue then think of their stance and write a text to argue it. The elaboration might be by taking the main ideas from the passages with their own ideas and examples to combine (Grabe \& Zhang, 2013). This task type, in fact, is not only upon reading input but also in listening skill. In the TOEFL test for example, the students or test takers might be asked to compose or summarize, synthesize their opinions after they listen to a text. As such, reading or listening text are regarded as an alternative writing task serving as a tool highlighting topical information, text rephrasing blueprint, and writing evaluation (Hayes, 1996).

Progress reports in the field have shown different findings. Integrated task is still considered difficult as the students have limited reading and writing proficiency, the challenge of reading long passages, a lack of fluency in reading and limited L2 background knowledge, and relatively little experience (and practice) integrating reading and writing skills for academic purposes. Besides, students also face challenges with L2 reading/writing tasks that require a large amount of inferencing (Grabe \& Zhang, 2013; Zhang, 2017). Apart from those mentioned the factors that affect performance on such tasks contributed to the quality of writing. For example, different test taker variables on the performance on integrated task might lead and influence task difficulty (Cho, Rijmen, \& Novák, 2013). Differently, the quality of performance on RTW tasks might be determined by human raters who make scores. Rater and rater-related interaction effects account for the considerable degree of variance in ratings. In this context, the rater variable is one of the main consideration and often affects score reliability in assessing students' writing quality (Barkaoui, 2014; Ling, Mollaun, \& Xi, 2014; Plakans, Gebril, \& Bilki, 2016; Shin \& Ewert, 2015; Yan, 2014). Along with the same line, regardless of analytic rating domain could capture the difference in variability of test takers' proficiency utilized in the reading to write (RTW) task, person and rater facets contributed to score variability in students' writing quality (Cho, Rijmen, \& Novak, 2013; Kuiken \& Vedder, 2014; Shin \& Ewert, 2015; Zhang, 2017). As such, those two variables need to be taken into account. Meanwhile, In'nami \& YoKoizumi (2016) emphasized that context, methods, scoring criteria, might lead to varied performance over tasks. Consequently, the task should be constructed in such a way that it really measures what to measure.

Thus, empirically, Reading to Write (RTW) as an integrated task might be seen differently in the context of its focus. This might be seen as a learning tool as the focus is on skill combination and source use (Knoch \& Sitajalabhorn, 2013). Yet, this tends to be considered as an alternative task (Hayes, 1996). This provides a topical idea, text revision types, and writing assessment, (Shin \& Ewert, 2015). However, regardless of how it is viewed, reading to write task is concerned with the ability in the sense of reconstructing any single information from the source text which, in turn, be synthesized into students' composition. As such, the task refers to the process level which influences and affects their understanding and the ability during the task completion. However, to date the examination toward the level where the integrated task is applied has not yet been sufficiently investigated. In this regard, a clear picture of students' writing quality needs to be examined for the sake of having a clear insight into what and how the integrated task should be employed.

\section{Method}

This study was carried out in 2020. Twenty-two students of English Study Program, enrolled in a single class, participated in the study. There were seven males and fifteen females. Before entering the college, they studied English for 6 to 8 years including the time in which they were given treatment. At the time of the investigation, the subjects were taking a compulsory 100 minutes essay class. Sentence writing course was given in advance, as a requirement to the essay class and all succeeded up to this level. All the participants have not taken any standardized English proficiency test.

This is a within group- experimental study that utilized a repeated measure design. Counterbalance technique was utilized to control the treatment order effect. Each of the students was given both types 
of task in which they had to write an argumentative essay twice both integrated and independent. Before asking the students to write, in the first session, the researcher divided the students into two sub-groups. The first group consisting of eleven students was given an independent (IND) writing task and the second group involving the rest eleven students were given an integrated (INT) task. Both were given 10 minutes to read a passage, and then write their essay in 30 minutes. In the following session, the task administrations are switched.

Two topics with equal complexity were selected after consulting with their English teacher. The topic for the first session that was given to both independent and integrated tasks was about the teacher knowledge and ability. The second session was about the social status and material possession. Both topics convincingly and effectively held the students' interest and elicited clear standing points generating their idea for argumentation. Each student was asked to write an essay consisting of 400 hundred words in 40 minutes based on the topic given.

Holistic scoring rubric was applied to score students writing, two experienced teachers with master's degrees and are still taking a doctoral program in English language department participated in the scoring process. For the sake of subjectivity, the teacher and researcher were not involved as the raters. After writing activity, the researcher coded the essays based on the names and was given to the raters with anonymous work. The scores then were analyzed using descriptive statistics which in turn were followed by inferential statistical analysis (Wilcoxon signed rank test -WSRT) to compare the quality of students' writing produced through both task types.

\section{Findings and Discussion}

\subsection{Findings}

The primary goal of this study is to investigate the difference between the quality of students' writing which is composed based on integrated and independent tasks. The result of descriptive statistical analysis in Table 1 showing the means of the writing using integrated task (Reading to write) was 3.54. Meanwhile, the means of writing using independent task was 3.36. The means of both writing, in which integrated tasks are bigger than independent were analyzed by using Wilcoxon Signed Ranks Test (WSRT).

Table 1. Descriptive Statistics of the Quality of Independent and Integrated Writing Task

\begin{tabular}{cccccc} 
Group & $\mathrm{N}$ & Mean & Std. Deviation & Min & Max \\
\hline INDQ & 22 & 3.3636 & .72673 & 2.00 & 5.00 \\
INTQ & 22 & 3.5455 & .59580 & 3.00 & 5.00 \\
\hline \multicolumn{2}{c}{ a. } & INDQ = Independent Task Group & & & \\
b. & INTQ = Integrated Task Group & & &
\end{tabular}

Table 2. Rank of Task Types

\begin{tabular}{clccc}
\hline & & N & Mean Rank & Sum of Ranks \\
\hline INTQ - INDQ & Negative Ranks & $4^{\mathrm{a}}$ & 5.88 & 23.50 \\
& Positive Ranks & $7^{\mathrm{b}}$ & 6.07 & 42.50 \\
& Ties & $11^{\mathrm{c}}$ & & \\
& Total & 22 & & \\
\hline
\end{tabular}

a. INTQ $<$ INDQ

b. INTQ $>$ INDQ

c. INTQ=INDQ

With respect to the ranks as displayed in Table 2, there were four students belonging to a negative rank. It means that the students who were given an integrated task got lower score than the students who were given an independent task. Seven students were in positive rank which means that the integrated task gives more benefit toward the quality of writing than the independent task. Meanwhile, eleven students were in an equal position. They got the same scores indicating that their quality of writing was similar as they wrote and were treated by both the integrated and independent task. This indicates that the integrated task did not affect the majority of the students' writing quality. The integrated task results were only differently found in seven students whose scores were better than as they were asked to write using independent tasks. 
Table 3. Wilcoxon Signed Ranks Test

\begin{tabular}{cc}
\hline & INTQ - INDQ \\
\hline Z & $-.884^{\mathrm{b}}$ \\
Asymp. Sig. (2-tailed) & .377 \\
\hline
\end{tabular}

In response to the research question and regarding the effectiveness of using integrated task yielded surprising results as shown in Table 3. Based on negative rank $\left({ }^{b}\right)$, the result of the analysis indicated that the quality of students' writings using integrated (INTQ) task (Reading to Write) were not significantly different from those who were given the independent task $(Z=-.884, p>0,05)$. It means that students could write essays in an equal quality regardless of the task types. Saying it differently, the facilitation of reading to write was not effective.

It is notable that the three raters used the same scoring rubric for both independent and integrated task. What is meant here is that the focus of the raters was not only on the products so long the rubric embodies them in the criteria but also language use component was taken into consideration. In addition, holistic rating raters' attention are concerned much more on grammar and vocabulary as the linguistic features than rhetorical features in determining the overall quality of essay. Regarding the feedback, the students writing was more or less dealt with those aspects. This is to say that the grammar and vocabulary are regarded as being bad which, in turn, definitely influence the rhetoric features development.

\subsection{Discussion}

With respect to the gap, this present study examined the effect of the integrated task reading to write (RTW) task toward the quality of students writing in the level of college students who have learnt English for many semesters. The counterbalancing effect was fulfilled since the students were divided into two groups in terms of having an opportunity in writing using integrated and independent task. As such, the method in question was meaningful to avoid experience factors and being fatigue toward the writing production.

The result of this present study is beneficial to our comprehension of the concept of reading to write (RTW). As such, this present study might help us to justify the way of employing the task type and determine the quality of students' writing. This is to say that understanding the sort of writing atmospheres and tasks are needed and more beneficial for bringing students toward increasingly more fluent and coherent expression of their ideas, experiences, and feelings in composing an essay. Moreover, as the area of second or foreign language, writing embraces the authenticity and meaningfulness of relating writing to other skills (Plakans, 2010). Consequently, language teachers and testers should have a good understanding of how writers deal with and compose for integrated tasks.

In a study which was conducted by Gebril \& Plakans (2013) in the integrated tasks, the source text provides language support. Some keywords and ideas might be taken by the writers which lead them to write a longer essay. Besides, having a number of words in the writing are the logical consequence of having good language proficiency in comprehending the source text. Likely, the nature of integrated tasks is to force the students to process the source materials, understand the idea, synthesize and present that source information into writing (Plakans et al., 2016). The requirement to integrate the sources in integrated task goes with an expectation that the writers can get some input which might be helping them to generate their ideas. This, definitely, would be beneficial in contributing to a higher proficiency of the writers in producing writing quality as a product involving the task representation and the writing itself. In agreement with the findings above, some previous studies also found that reading to writing task had a significant effect on students' writing, (Zhang, 2017). There was a significantly better performance as the students employed reading to write tasks. What language they have in the reading passage was proper and helpful to do an essay. In addition (Plakans et al., 2016) found that the contribution of integrated writing tasks increases as score level increases.

However, the findings of this present study contrasts to those previous findings mentioned. As it has been proved, the WSRT analysis yielded surprising results. There was no significant difference between the use of independent and integrated task in the quality of students' writing. Although it was assumed that the integrated task might be better in terms of the quality compared to the independent one, providing exposure to writing in which other skills are integrated should not ideally bridge the needs of generating ideas into a discourse level as a product. 
This present study mirrors the report of (Plakans, 2010) noting that integrated does not mean to make writing easier. The source text might be helpful for some students in understanding the topic of the passage which is so-called content schematic task representation. However, some might have difficulties in writing or even to consider it as a barrier. Moving further, it is worth mentioning that writing using independent task deals with the why the students cope with their background knowledge regarding the topic as they concern themselves. Writer's background knowledge seems influenceable in the point of the interpretation toward the given task (integrated and independent tasks). As such, it would be beneficial to generate their ideas into writing. In this present study, data of the raw score showed that few students could do the writing well. In this context, they might have good background knowledge which goes together with the language competence accumulation of the topic which could lead them to generating the idea in writing an essay. Meanwhile, the independent task requires more writing and cognitively demands more generation, planning, and organization than in the integrated tasks in which ideas from reading are definitely summarized.

Moreover, regarding the scores, without having an exposure of a passage, the students, in fact, produced a good quality of writing. It was found that there were four students out of twenty-two who have higher scores as they were asked to write by independent task than the students who were treated by the integrated task. In agreement with previous research, (Plakans, 2010), other aspects such as the background knowledge of the topic given might contribute to the writing. While the integrated task was not really supporting as it was assumed. Four students' writing indicated having no effect on writing quality. This, then, weakened the previous studies of (Barkaoui, 2014; Gebril \& Plakans, 2013) as previously mentioned.

Another issue came up to this surprising fact is that the complexity of the demands in the task compared to the independent one leading to the reconsideration or so-called recirculation of ideas in the process of writing. In this regard, language proficiency might be one of the sources toward such problem. This present study corroborates the previous findings emphasizing the contribution of writing ability in English and English language proficiency are beneficial to the score of the tasks, (Barkaoui, 2014; Gebril \& Plakans, 2013; Yang \& Plakans, 2012). However, it is not the only one and one only. Noticing the feedback from the three raters, students have some problems in language features resulting in the scores.

This is to say that the types of task do not really matter in this present study. The total number of students whose writing scores were the same, both independent and integrated, does not reflect the finding of Abrams \& Byrd (2017) saying that the task type improved the overall writing quality involving grammatical accuracy and lexical richness. In agreement with Yang \& Plakans (2012) and Plakans (2010), students' performance in writing mainly rely on their strategy employing their language into production level. As such, the language production deals with an understanding of the information from the source text. In other words, this may indicate that task types are not really influential in the students' writing but tend to be influenced by other factors which contribute to the writing.

What is more interesting is that this embraced the students on average, no matter, they belong to the independent or integrated task. Yet, there were four students who were supposed to at least better as they belong to integrated but then, are negatively positioned from independent. Besides, there were also four who are better than those employed independent tasks. Again, the raw score confirmed that their language proficiency was another aspect to cope with. Again, this corroborates the findings emphasizing the language proficiency and accuracy can result in writing an essay, (Barkaoui, 2014; Gebril \& Plakans, 2013; Zhang, 2017). Thus, types of tasks do not guarantee the writing quality. Many other aspects such as language proficiency, accuracy and background knowledge involving the ability to generate idea into a discourse should be taken into account.

By and large, the students' writing quality by means of the integrated task was not significantly different from the independent one. The majority of students writing remain the same in terms of having the effect of integrated task (RTW. Then, no matter to what level students belong to, high, medium or low, aside from task types, discourse competence and knowledge background are highly required. In this regard, the two aspects in question might be of benefit in constructing ideas from sentences to a text in employing a certain task type and its complexity. When we choose tasks, it might be better to consider those as they also affect writing quality. Any single provided task will be a features' bundle. We might have a task that has simple input, involves the here-and-now and has the same topic (features making the task easy) but the information covers much more elements and is not well-constructed (features making the task complex). Briefly, a task may be simple in some ways but complex in others. 


\section{Conclusion}

The study found that the use of integrated task was not more effective than the independent task. Regardless of task types, the result of this study should be recognized as a standing point to shed light on considering other aspects of the quality of writing. Therefore, this present study provides an implication both theoretically and pedagogically. Regarding the theoretical implication, this study may contribute to the existing conceptual framework of how to design features and task complexity with the involvement of discourse competence. Meanwhile, the pedagogical implication is concerned with what and how a task type is employed. With the consideration of knowledge background and language proficiency, the instructional techniques and approaches to employ a task type are highly needed in gaining students' writing quality.

Regarding the limitations of this present study, this present finding provides possible paths for further studies. First, the understanding of source texts, in fact, might be beneficial or being complex for the students or writers. It might be better if further research studies deal with how the correlation of understanding the source text, language proficiency with writing quality. Besides, a further research might be able to reveal the extent of students' background knowledge on the topic given that influence the quality of writing. As such, it deals with how the students transfer their knowledge by means of a language they possess following the possible topic given. Thus, the relation of topic familiarity, background knowledge and the language used toward writing quality is another challenging topic to deal with in the future.

Author contribution

Funding statement

Conflict of interest

Additional information

\section{Declaration}

: The author confirms sole responsibility for the following: study conception and design, data collection, analysis and interpretation of results, and manuscript.

: The author declared no potential conflicts of interest with respect to the research, authorship and/or publication of this article.

: The author declares no conflict of interest.

: The author received no financial support for the research and/or authorship of this article.

\section{REFERENCES}

Abrams, Z., \& Byrd, D. R. (2017). The effects of meaning-focused pre-tasks on beginning-level L2 writing in German: An exploratory study. Language Teaching Research, 21(4), 434-453. https://doi.org/10.1177/1362168815627383

Barkaoui, K. (2014). Examining the impact of L2 proficiency and keyboarding skills on scores on TOEFL-iBT writing tasks. Language Testing, 31(2), 241-259. https://doi.org/10.1177/0265532213509810

Cho, Y., Rijmen, F., \& Novak, J. (2013). Investigating the effects of prompt characteristics on the comparability of TOEFL iBTTM integrated writing tasks. Language Testing, 30(4), 513-534. https://doi.org/10.1177/0265532213478796

Cumming, J., Clark, S. E., Ste-Marie, D. M., McCullagh, P. and Hall, C. 2005. The functions of observational learning. Psychology of Sport and Exercise, 6, 517-537.

Delaney, A. Y. (2008). Investigating the reading-to-write construct. Journal of English for Academic Purposes, 7, 140-150. https://doi.org/10.1016/j.jeap.2008.04.001

Gebril, A., \& Plakans, L. (2013). Toward a transparent construct of reading-to-write tasks: The interface between discourse features and proficiency. Language Assessment Quarterly, 10(1), 9-27. https://doi.org/10.1080/15434303.2011.642040

GhaVamnia, M., Tavakoli, M., \& Esteki, M. (2013). The effect of pre-task and online planning conditions on complexity, accuracy, and fluency on EFL learners ' written production. Porta Linguarum, 20(junio), 3143.

Grabe, W., \& Zhang, C. (2013). Reading and writing together: A critical component of English for academic purposes teaching and learning. Tesol Journal, 4(1), 9-24. https://doi.org/10.1002/tesj.65 
Grace, D., \& Malang, U. N. (2018). Relationships among writing and reading as a respond to critical journal review. International Journal of Emerging Technologies in Learning, 8(1), 341-344.

$\mathrm{Gu}, \mathrm{L}$. (2014). At the interface between language testing and second language acquisition: Language ability and context of learning language. Language Testing, 31(1), 111-133. https://doi.org/10.1177/0265532212469177

Hayes, J. R. (1996). A new framework for understanding cognition and affect in writing. In C. M. Levy \& S. Ransdell (Eds.), The science of writing: Theories, methods, individual differences, and applications (p. 127). Lawrence Erlbaum Associates, Inc.

In'nami, \& YoKoizumi, R. (2016). Task and rater effects in L2 speaking and writing: A synthesis of generalizability studies. Language Testing, 33(3), 341-366. https://doi.org/10.1177/0265532215587390

Knoch, U., \& Sitajalabhorn, W. (2013). A closer look at integrated writing tasks : Towards a more focussed definition for assessment purposes. Assessing Writing, 18(4), 300-308. https://doi.org/10.1016/j.asw.2013.09.003

Kuiken, F., \& Vedder, I. (2014). Rating written performance : What do raters do and why? Language Testing, 31(3), 329-348. https://doi.org/10.1177/0265532214526174

Leaper, D. A. (2014). The influence of prompt on group oral tests. Language Testing, 31(2), 177-204. https://doi.org/10.1177/0265532213498237

Ling, G., Mollaun, P., \& Xi, X. (2014). A study on the impact of fatigue on human raters when scoring speaking responses. Language Testing, 31(4), 479-499. https://doi.org/10.1177/0265532214530699

Nitta, R., \& Nakatsuhara, F. (2014). A multifaceted approach to investigating pre-task planning effects on paired oral test performance. Language Testing, 31(2), 147-175. https://doi.org/10.1177/0265532213514401

Pertiwii, Dian, Ngadiso, and Drajat, N. A. (2018). The effectiveness of dictogloss in teaching writing skill viewed from students's motivation. International Journal of Emerging Technologies in Learning, 8(1), 366-380.

Plakans, L. (2009). Discourse synthesis in integrated second language writing assessment. Language Testing, 26(4), 561-587. https://doi.org/10.1177/0265532209340192

Plakans, L. (2010). Independent vs. integrated writing tasks: A comparison of task representation. TESOL Quarterly, 44(1), 185-194. https://doi.org/10.5054/tq.2010.215251

Plakans, L., Gebril, A., \& Bilki, Z. (2016). Shaping a score : Complexity , accuracy, and fluency in integrated writing performances. Language Testing, 1-9. https://doi.org/10.1177/0265532216669537

Rassaei, E. (2014). Effects of textual enhancement and input enrichment on L2 development. Tesol Journal, 1-21. https://doi.org/10.1002/tesj.149

Sawaki, Y., Quinlan, T., \& Lee, Y. (2013). Understanding learner strengths and weaknesses: Assessing performance on an integrated writing task. Language Assessment Quarterly, 10(1), 73-95.

Shi, L., \& Ma, Z. (2016). Application of visual interactive concept map in college English writing teaching. Internaltional Journal of Emerging Technologies in Learning, 11(11), 32-36.

Shin, S., \& Ewert, D. (2015). What accounts for integrated reading-to-write task scores ? Language Testing, 32(2), 259-281. https://doi.org/10.1177/0265532214560257

Thi, M., Nguyen, T., Pham, H. T., \& Pham, T. M. (2015). The effects of input enhancement and recasts on the development of second language pragmatic competence. innovation in language learning and teaching, (April 2015), 37-41. https://doi.org/10.1080/17501229.2015.1026907

Wette, R. (2014). Teacher-led collaborative modelling in academic L2 writing courses. ELT Journal, 1-10. https://doi.org/10.1093/elt/ccu043

Wolfersberger, M. (2013). Refining the construct of classroom- based writing-from-readings assessment: The role of task representation. Language Assessment Quarterly, 10(1), 49-72. https://doi.org/10.1080/15434303.2012.750661

Yan, X. (2014). An examination of rater performance on a local oral english proficiency test : A mixed-methods approach. Language Testing, 31(4), 501-527. https://doi.org/10.1177/0265532214536171 
Yang, H.-C., \& Plakans, L. (2012). Second language writers strategy use and performance on an integrated reading-listening-writing task. TESOL Quarterly, 46(1), 80-103. https://doi.org/10.1002/tesq.6

Zhang, X. (2017). Reading - writing integrated tasks, comprehensive corrective feedback, and EFL writing development. Language Teaching Research, 21(2), 217-240. https://doi.org/10.1177/1362168815623291 